\title{
Evaluating Model of Road Traffic in Open Housing Estate Based on Cellular Automaton
}

\author{
Jialin Wen ${ }^{1}$, Min Zou ${ }^{2}$ \\ ${ }^{1}$ Electrical and Information College, Jinan University, China \\ ${ }^{2}$ School of Translation Studies, Jinan University, China \\ Correspondence: Jialin Wen, Electrical and Information College, Jinan University, Qianshan Road 206, Zhuhai, China. \\ Tel: 1-582-057-8305. E-mail: 1094886064@qq.com
}

Received: February 22, 2017 Accepted: March 17, $2017 \quad$ Online Published: April 11, 2017

doi:10.5539/ijsp.v6n3p99

URL: https://doi.org/10.5539/ijsp.v6n3p99

\begin{abstract}
It has been referred in document issued by the State Council recently that China will promote the block system gradually in the future, no more enclosed residential compounds will be built in principle, and existing residential and corporate will open up step by step as well. The proposal of open area quickly aroused a heated discussion in the whole society. In addition to the most basic security issues, it is one of the main topics that whether the open district can really optimize the road network structure and improve the traffic in the end.

Based on the cellular automata model and the actual situation, this paper simulates the traffic flow around the residential area, establishes motor vehicle driving model and makes a comprehensive evaluation of the surrounding road traffic after the opening of different types of residential area. According to the result of the index, it shows that three structures of residential area can relieve the burden of urban traffic flow while one structure of residential area that will aggravate the burden of urban traffic flow. Finally, the paper comes to the conclusion that excessive traffic flow of the trunk road which has adverse effect on road traffic.
\end{abstract}

Keywords: cellular automata, traffic flow, motor vehicle driving model, structure of residential area

\section{Introduction}

Recently the State Council "guideline Proposals on Doing a Good Work of Urban Planning Management" has sparked widespread concern. It is mentioned in article 16 of the document that China will promote the block system gradually in the future, no more enclosed residential compounds will be built in principle, and existing residential and corporate will open up step by step as well. Although the opening of gated residential communities can reduce the traffic volume carried by the road to a certain extent, the increasing vehicles in intersection areas of main roads around the communities may cause traffic jams more easily. Therefore, it is of great theoretical and practical significance to analyze the influence of opening up gated residential communities on road capacity.

At present, the researcher Kuang Xianyan has developed the urban mixed traffic micro simulation system which conforms to the mixed traffic characteristics of our city, being a powerful tool to research and analysis the traffic engineering; Li Xiangpeng discussed the possibility of opening the residential area and put forward the relevant measures to improve the traffic system; Zhang Biao studied the traffic congestion diffusion mechanism of the intersection road and its influence on the traffic capacity; The scholar Jin Long studied the relationship between the driving mentality and the stability in signal-less intersection; Deng Feng studied the distinction between enclosed residential area in our country and western private community; Li Xiaofeng worked out the urban residential planning strategy; Hu Zhiyong analyzed the impact of the residential area on traffic; Qin Ge studied the coordination between the planning mode of urban enclosed residential area and development of urban traffic.

The research objective of this paper is that whether the open road will reduce the burden of surrounding roads, how the surrounding road traffic will change after opening different residential areas, and how to make the district open rationally.

In view of the fact that there are few open communities in our country, in order to evaluate the indicators before and after the opening, it is necessary to simulate the traffic flow under the different road structures which are similar to the real situation and can change with the real situation to get the data of the average vehicle speed in the road network, the average travel time on the road section and so on.

Then, a vehicle driving model based on cellular automata is established, which divides the roads around the residential 
area into straight road, signalized intersection and signal-less intersection. This paper adopts straight road to simulate the straight lane of the community entrance. Traffic flow is simulated by using signalized intersection to simulate the traffic flow at the crossroads near the residential area, and the traffic flow at the entrance and exit of the residential area is simulated with the signalized intersection. In this way, the traffic flow data can be obtained before and after the opening of residential area.

This paper also takes more common structures of residential area in real life into account, classifies them, and tries to open them. Then, based on four kinds of basic structures of residential area, the location of the residential area on the real traffic road is simulated combined with common road structure.

In order to compare the influence of various types of communities on the roads before and after the opening, this paper needs to use the model to calculate these four kinds of basic structures of residential area, and obtain a series of data related to traffic flow, then use the evaluation index to quantitatively describe the influence on traffic before and after opening and judge whether it will reduce the burden of the main road. The paper then makes a further calculation in order to study whether the traffic volume of the main road has an impact on road traffic.

Finally, according to the evaluation of various indicators of the structures of residential areas, this paper makes a reasonable analysis of the influence of opening up residential areas on capacity of the road from the perspective of traffic.

\section{Establishment of the Motor Vehicle Driving Model}

In order to study the mathematical model used to study the influence of opening residential area on the surrounding roads, this paper needs to simulate the traffic flow under different road structures which are similar to the real situation and can change with the real situation, and can get the average vehicle speed, the average travel time on the road section, etc. Next, this paper will build a motor vehicle driving model based on Cellular Automata (referred to as CA model) to analyze the impact of open area on the surrounding roads. The length of 1400 cells in each lane was analyzed.

\subsection{Motor Vehicle Driving Model on Straight Lane}

Combined with China's driving rules and the actual situation of the road to get the linear lane under the motor vehicle driving rules are as follows:

(1) Drive Right Rules.

When the right-hand rule is applied, the vehicle's traffic needs to meet some of the rules of the cellular automaton (the rules listed are descending first, that is, if the first rule is met and the latter is ignored)

Turn to the right lane if vehicle distance $\Delta \mathrm{D}$ on the right lane is longer than $\Delta \mathrm{D}_{0}$.

- Apply the rule of free driving in Car Following Principle if vehicle distance $\Delta \mathrm{D}$ is longer than $\Delta \mathrm{D}_{0}$.

- If vehicle distance $\Delta \mathrm{D}$ on the left lane is longer than $\Delta \mathrm{D}_{0}$, the probability of using Overtaking Model is $\mathrm{P}_{0}$, the probability of using Car Following Model is 1- $\mathrm{P}_{0}$.

(2) Vehicle Generation Rules

The car generates rules that simulate the random arrival of the car at the end of the city road where the first six cells in the cell automaton are set to be the vehicle-generated area. This paper assumes that the arrival of each vehicle obeys the Binomial Distribution.

$t_{s}$ stands for sampling time interval, $N$ is the number of cars that arrive in a period of $t_{s}$. In this way, $N$ is approximately subject to Poisson Probability Distribution. The probability of $N$ is $P_{t s}(N)$, and

$$
p_{t s}(n)=\frac{\lambda^{N}}{N !} e^{-\lambda}, N>0
$$

In this paper, $t_{s}$ equals one second. We can give $N$ a expected value between 0 and 3.6. $N$ is the total number of all vehicles arriving every second, and the expected value of $N$ can effectively reflect the traffic condition. The smaller the $\lambda$, the smaller traffic density; the larger the $\lambda$, the larger the traffic density. Therefore the paper evaluates different traffic conditions (heavy or light the traffic flow is) by assigning different values to $\lambda$. Once the value of $\lambda$ is given, the random number of vehicles arriving every second and the number of lanes where the vehicle is randomly assigned can be obtained.

(3) Car Following Principle

Vehicle follow-up is an important way to drive vehicles in road traffic. In the road network model system based on travel track, the three conditions are followed: 
- The leading and following vehicle are in the same driving track, and the leading vehicle is right in front of the following vehicle;

- The leading and following vehicle are in the different driving track, and the following car is right on the downstream lane where the leading vehicle is about to drive;

- The front vehicle is on the dynamic track and the end of the dynamic track is on the driving track of the vehicle. The distance between the two cars is the distance between the following vehicle and the frontal projection point of the leading vehicle on the driving track of the following vehicle.

(4) Overtaking Rules

The driver will not overtake unless forced, overtaking is sometimes dangerous, under the drive right rules, the vehicle not only need to overtake successfully, but also have to to be able to return to the previous lane. Therefore, overtaking is limited.

- Overtaking situation (both to be satisfied):

- The distance of the two vehicles in the target lane $\Delta D$ is greater than $\Delta D_{0}$

- The following vehicle is faster than the leading vehicle.

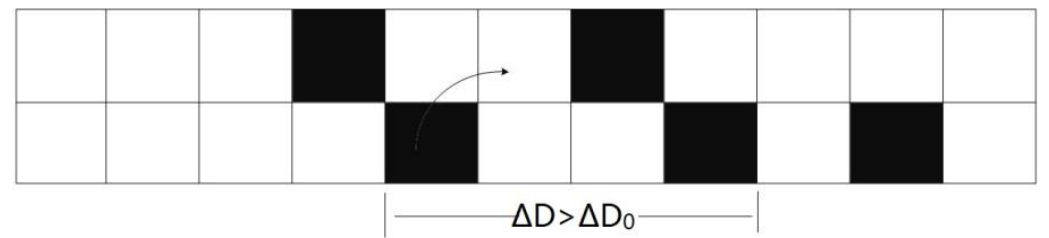

Figure 1. The CA Model under the Overtaking Rules

The probability of $P_{0}$ which is determined by vehicle A and vehicle B in front of vehicle A determines whether the driver chooses to overtake another vehicle. Let $V_{1}$ represents the speed of vehicle $\mathrm{A}, V_{2}$ represents the speed of vehicle $\mathrm{B}$, then the probability satisfies the following formula:

$$
P_{0}=\left\{\begin{array}{l}
1-0.9 \cdot e^{V_{1}-V_{2}}, V_{1}<V_{2} \\
0.1, V_{2}<V_{1}
\end{array}\right.
$$

This article can reasonably assume that the greater the difference in the speed of the two vehicles, the more likely that the following vehicle will accelerate with the probability distribution also meeting the trend of changes.

\subsection{Motor Vehicle Driving Model on Entrance and Exit of Signal-less Residential Area}

Entrance of residential area can be approximately understood as a T-junction without signals, the following article will refine the rules of CA model, simulate driving state of motor vehicle near signal-less entrance of residential area.

In real life, the general vehicle tend to maintain a large front distance in the residential area through the entrance, so here this paper assume that most drivers are rational and conservative. If the road outside the residential area is main road, the road in the residential area is secondary road. The rule in residential area entrance is set as follows:

The vehicle which arrived at the location A first turn, only if it is on the right lane can it turn right. Therefore only on the right lane can the vehicle turn right, as shown in Figure 2, so there is no road conflict.

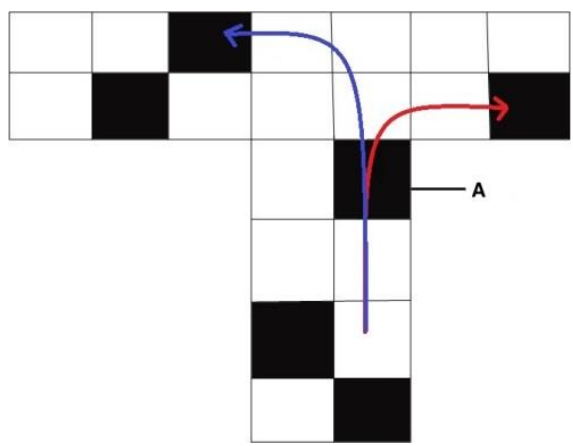

Figure 2. Signal-less T-Junction 
In the queue length within the vehicle through the intersection of the moment, most of the vehicles in this section of the road intersection at the traffic flow is critical to accelerate the departure, so the vehicle at this time relative to the free movement model, the lower the probability of lower some.

Based on these rules in real life, this paper sets the rules for cellular automata as follows:

(1) Acceleration:

$$
\begin{aligned}
& v^{\prime}=\min \left(v_{n}+1, v_{\max }\right) \\
& v_{\max }=\left\{\begin{array}{l}
5, \text { green } \\
2, \text { red }
\end{array}\right.
\end{aligned}
$$

(2) Deceleration:

$$
v^{\prime}=\min \left(v_{n}, d_{n}\right)
$$

$d_{n}$ is the number of empty cells in front of the vehicle, the distance between the intersection and vehicle closest to the intersection $d_{n}=x_{\text {signal }}-x_{n}$.

\subsection{Motor Vehicle Driving Model on Signalized Crossroad}

Opening the residential area has some effect on signalized crossroads nearby to some degree. Therefore, it is necessary to analyze the motor vehicle driving model near the crossroads. This paper will refine the CA model according to the rules under the signalized crossroads.

When the traffic light at the intersection is green, the running status of the vehicle is not affected, and when the signal light turns red, the acceleration and deceleration rules of the vehicle are affected, and the vehicle needs to decelerate to wait for the next green light to pass. Then make improvements at the signal-less intersection of the CA model to. If the horizontal direction of the road is main road, the vertical direction of the road is auxiliary road, then signalized crossroads should meet the following rules:

\section{(1) Acceleration Process under Green Light}

In the queue length of the vehicle when the lights turn green light at the moment, most of the vehicles in this section of the road intersection at the traffic flow is essential to accelerate the departure, so the vehicle at this time relative to the free movement model, the probability of deceleration Lower.

(2) Deceleration Queuing Model under Red Light

In the queue of the vehicle, due to the impact of the signal light, when the light turns red, most of the vehicles have to decelerate and wait in line, so the probability of decelerate in the model is relatively higher than the model of free movement.

(3) Relationship between turning left and right (as shown in Figure 3)

Turning right precedes turning left, turning precedes going straight. Turning left is a big curve, turning right is a small curve. Because when the light is green, the first vehicle to arrive at the position A goes first, when the light is red, all vehicles have to wait at the intersection. Therefore, there is no position conflict in this intersection.

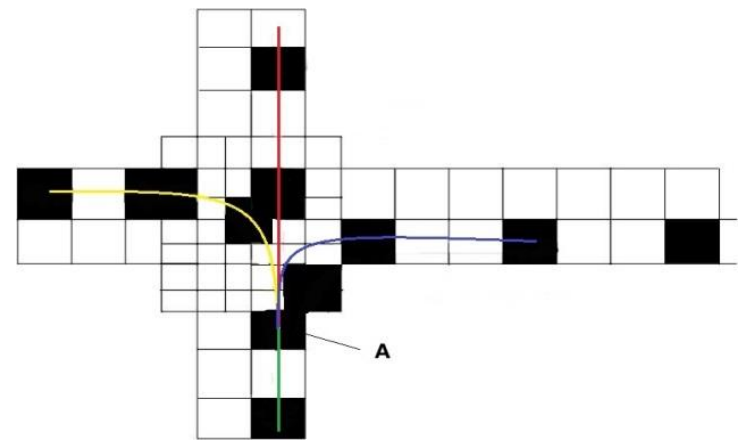

Figure 3. Signalized Crossroad 
Based on these rules in real life, this paper sets the rules for cellular automata as follows:

(1) Acceleration:

$$
\begin{gathered}
v^{\prime}=\min \left(v_{n}+1, v_{\max }\right) \\
v_{\max }=5
\end{gathered}
$$

(2) Deceleration:

$$
v^{\prime}=\min \left(v_{n}, d_{n}\right)
$$

$d_{n}$ is the number of empty cells in front of the vehicle, the distance between the intersection and vehicle closest to the intersection $d_{n}=x_{\text {signal }}-x_{n}$.

\section{Evaluation of Structures of Different Kinds of Open Residential Areas}

\subsection{Establishment of Different Basic Structures of Residential Areas}

The following shows plan of some domestic communities, it is not difficult to sort out the internal structure of the enclosed residential area after graphical.

For the single-entrance residential area, because there is only one closed path for residents to contact with traffic outside, so even if the type of community open, the road network structure can not be optimized, the road capacity and traffic conditions can not be improved. So it is unnecessary for the single-entrance residential area to open.

For the double-entrances residential area, the distribution of its entrances are mainly the following three structures, then the paper will analyze the three kinds of structures in order:

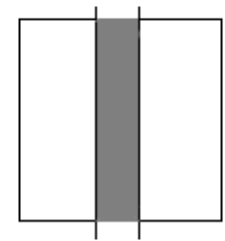

Type I

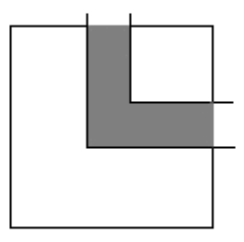

Type II

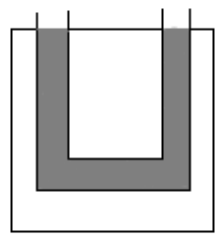

Type III

For the triple-entrance residential area, there is only one structure of its distribution of entrance:

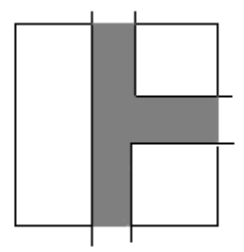

Triple-entrance Type IV

For the residential area with four or more entrances, its structure of distribution of entrance can be simplified as one of the three cases above, so this article will not discuss those situation separately.

\subsection{Basic Construction of Pavement Structure}

Taking the reality of most of the urban roads in China into account, this paper will graph the traffic road structures in reality, and divide them into three basic structures: two-way straight lane, T-type intersection and crossroads.

The following will discuss the specific situation of the combination of structure of residential area and urban road structure, and the model established by motor vehicle driving model is used to quantitatively compare the influence of opening different kinds of residential area on road traffic.

In order to facilitate the calculation and comparison, this article sets the length of unilateral of traffic-opening residential area is $500 \mathrm{~m}$, the branch spacing is $250 \mathrm{~m}$ long. In the crossroad, the crossing time under green light is $25 \mathrm{~s}$, the time for 
turning left under green light is 20 s and the waiting time under red light is 55s. The time is set during 8: 00-9:30 a.m. According to the cellular automata model established in this paper, the morning peak period is simulated, and the traffic flow in the early peak period is $1780 \mathrm{veh} / \mathrm{h}$.

\subsection{Different Structures of Residential Area on Different Types of Road}

This paper matches different basic structures of residential areas and different types of road which will be similar to the real combination between the residential area and the road. Then use the motor vehicle driving model to calculate the traffic flow around the residential area. And then a reasonable assessment of the traffic flow around the communities with different structures can be achieved.

\subsubsection{Combination of Double-entrance Type I Residential Area and Two-way Straight Lanes}

This combination simulates a situation in which a residential areas connects two non-adjacent roads, and the vehicle can quickly pass through two non-adjacent roads when the road is opened in the residential area, and the analysis of traffic flow near the combined model is shown in Table 1.

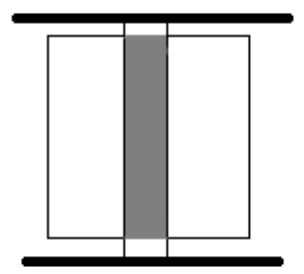

Table 1. Evaluation of the Combination of the Double-entrance Type I Residential Areas and the Two-way Straight Lane

Road Service Level Traffic Lights Service Entrances and Exits Evaluation of the Overall

Level at the Intersection Service Level Traffic Capacity of the Road

\begin{tabular}{cccccc}
\hline & $\begin{array}{c}\text { Average Main } \\
\text { Road speed }\end{array}$ & $\begin{array}{c}\text { Average Speed of Road } \\
\text { Network within the Residential } \\
\text { Area }\end{array}$ & $\begin{array}{c}\text { Average Delay } \\
(\mathrm{s} / \mathrm{veh})\end{array}$ & $\begin{array}{c}\text { Average Delay } \\
\text { Time }\end{array}$ & Road Capacity \\
\cline { 1 - 4 } Before & 43.2 & 40.6 & 13 & 5.5 & Decreased Burden \\
\hline After & 46.3 & 37.9 & 10 & 8.4 & \\
\hline
\end{tabular}

Compared the before and after of opening the district, it is not difficult to find that, due to the opening of the block road, the traffic on the main road can turn right, directly drive to another exit through the road in the residential area, which shares a portion of the traffic flow and reduces some of mileage on main roads. The impact of it is that the average speed of the road within the residential area is reduced. However, it did not affect the service level. Similarly, the service level of intersection with traffic lights (the crossroads) fluctuates at the same level as the service level of entrances and exits, both of which have little influence on residents. It is clear that the overall traffic capacity of the city has been improved and the burden has been slowed down. Considering the fact that the traffic flow in morning peak is high, it is generally believed that the opening of this type of residential area road can promote the development of urban traffic.

\subsubsection{Combination of Double-entrance Type II Residential Area and Crossroads}

This combination simulates a case where a residential area passes through two adjacent roads. If the traffic passes inside the residential area, the vehicle will no longer need to pass through the crossroads, and the traffic flow situation near the combined model is shown in Table 2. 


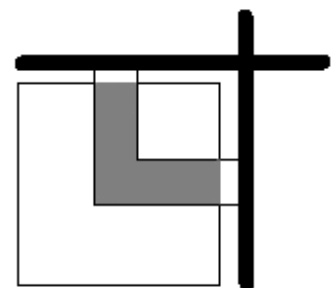

Table 2. Evaluation of the Combination of Double-entrance Type II Residential Areas and Crossroads

Road Service Level
Traffic Lights Service Entrances and Exits Evaluation of the Overall

Level at the Intersection Service Level Traffic Capacity of the Road

\begin{tabular}{cccccc}
\hline & $\begin{array}{c}\text { Average Main } \\
\text { Road speed }\end{array}$ & $\begin{array}{c}\text { Average Speed of Road } \\
\text { Network within the Residential } \\
\text { Area }\end{array}$ & $\begin{array}{c}\text { Average Delay } \\
(\mathrm{s} / \mathrm{veh})\end{array}$ & $\begin{array}{c}\text { Average Delay } \\
\text { Time }\end{array}$ & Road Capacity \\
\hline Before & 38.4 & 35.3 & 15 & 8.6 & Decreased Burden \\
\hline After & 42.2 & 30.1 & 14 & 13.3 & \\
\hline
\end{tabular}

Before and after the opening of the residential area, it can be found that the traffic on the main road can not only turn right at the front signal light, but also directly drive to the other exit through one of the entrance and exit of the residential area, which shares a portion of the traffic flow and increases the average speed of the traffic flow on main road. The impact of it is that the average speed of the road within the residential area is reduced to some extent. However, it did not affect the service level. Similarly, the service level of intersection with traffic lights (the crossroads) fluctuates at the same level as the service level of entrances and exits, both of which have little influence on residents. It is clear that the overall traffic capacity of the city has been improved and the burden has been slowed down. Considering the fact that the traffic flow in morning peak is high, it is generally believed that the opening of this type of residential area road can promote the development of urban traffic.

\subsubsection{Combination of Double-entrance Type III Residential Area and Two-way Straight Lane}

This combination simulates the fact that the two entrances and exits of a residential area pass through the same road. If it passes through the residential area, the vehicle will no longer need to pass through the road, and the traffic flow situation near the combined model is shown in Table 3.

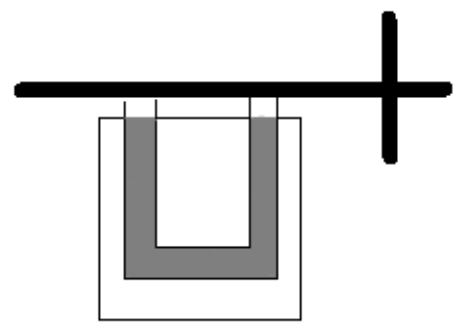


Table 3. Evaluation of the Combination of Double-entrance Type III Residential Area and Two-way Straight Lane

\begin{tabular}{|c|c|c|c|c|c|}
\hline & \multicolumn{2}{|c|}{ Road Service Level } & \multirow{2}{*}{$\begin{array}{l}\text { Traffic Lights Service } \\
\text { Level at the Intersection } \\
\text { Average Delay } \\
\text { (s/veh) }\end{array}$} & \multirow{2}{*}{$\begin{array}{c}\text { Entrances and Exits } \\
\text { Service Level } \\
\text { Average Delay } \\
\text { Time }\end{array}$} & \multirow{2}{*}{$\begin{array}{c}\text { Evaluation of the Overall } \\
\text { Traffic Capacity of the Road } \\
\text { Road Capacity }\end{array}$} \\
\hline & $\begin{array}{c}\text { Average Main } \\
\text { Road speed }\end{array}$ & $\begin{array}{c}\text { Average Speed of Road } \\
\text { Network within the Residential } \\
\text { Area }\end{array}$ & & & \\
\hline Before & 42.8 & 40.4 & 13 & 6.9 & \multirow{2}{*}{ Increased Burden } \\
\hline After & 38.7 & 33.5 & 18 & 15.4 & \\
\hline
\end{tabular}

Before and after the opening of the residential area, it can be found that due to the high traffic flow during the morning peak, some of the vehicle influx into the slip road of the residential area, which does not play the role diversion of traffic flow on the trunk, but to promote the influx of more vehicles into the trunk and slip road inside the residential area, resulting in further congestion of urban roads, making the average speed of traffic flow on the main road and the average speed of the traffic inside the residential area affected. As another exit has a synergistic effect, the congested trunk traffic flow becomes more congested, further increasing the average delay in the intersection with the signal lights and the entrances and exits, resulting in reduced service levels of the intersection with the lights and entrances and exits. Also, it increases the burden of urban roads. It is clear that this is due to the positive impact of the diversion of the slip road resulting from excessive traffic flow is less than the negative impact resulting from the simulation of the trunk traffic. The key to solve this contradiction is to reduce trunk traffic flow.

(4) Combination of Triple-entrance Residential Area and Crossroads

This combination of simulation is that three entrances and exits pass through three road. If the vehicle passes within the residential area, it can cross two parallel lanes without passing the crossroad or cross adjacent two lanes without passing the crossroad. The traffic flow situation near this combination model is shown in Table 4.

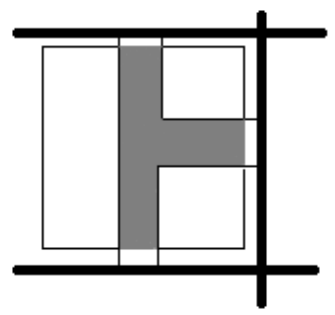

Table 4. Evaluation of the Combination of Triple-entrance Residential Area and Crossroads

Road Service Level
Traffic Lights Service

Level at the Intersection
Entrances and Exits

Service Level
Evaluation of the Overall

Traffic Capacity of the Road

\begin{tabular}{|c|c|c|c|c|c|}
\hline & $\begin{array}{l}\text { Average Main } \\
\text { Road speed }\end{array}$ & $\begin{array}{c}\text { Average Speed of Road } \\
\text { Network within the Residential } \\
\text { Area }\end{array}$ & $\begin{array}{c}\text { Average Delay } \\
\text { (s/veh) }\end{array}$ & $\begin{array}{c}\text { Average Delay } \\
\text { Time }\end{array}$ & Road Capacity \\
\hline Before & 43.3 & 40.4 & 14 & 8.9 & \multirow{2}{*}{ Decreased Burden } \\
\hline After & 45.2 & 39.4 & 8 & 10.3 & \\
\hline
\end{tabular}

Before and after the opening of the residential area, it can be found that, due to the particularity of the triple-entrance area, the opening will produce three new interchangeable branches, greatly share the pressure of the trunk, so there is nearly no effect on average speed of the slip road. It is more striking that, since the linkages of the three interchangeable branches 
are significantly larger than only one branch, the vehicle that originally needs to go through the signal light is significantly reduced, as can be seen from the significantly decreased average delay in the intersection with the signal lights. Similarly, the average delay time near the entrance is not affected too much. As a result, this paper considers that the road structure of this situation can not only effectively alleviate the road burden, but also has great potential for development.

\subsection{Road Situation around Residential Areas under Different Traffic Flow}

After discussing the combination of these residential areas structure and road structure, it is not difficult to find that the double-entrance type III residential area is not only unable to share urban road pressure, but also increase the pressure of urban road in other forms. It can be guessed that this phenomenon is related to traffic flow. Therefore, according to the motor vehicle driving model and some simulation data, as shown in Table 5, this paper will re-examine the surrounding traffic situation in the case of different traffic flow in the residential area, the specific indicators are as follows:

Table 5. Relationship between the Traffic Flow and the Vehicle Speed Simulated by Residential areaular Automata

\begin{tabular}{cccccccccc}
\hline Traffic Flow(veh/h) & 1149 & 1157 & 1173 & 1200 & 1425 & 1552 & 1642 & 1780 \\
\hline Average Speed on Trunk(km/h) & 57.9 & 54.6 & 49.9 & 46.6 & 45.3 & 45 & 43.1 & 42.8 \\
\hline Average Speed on Slip Road(km/h) & 59.5 & 58.1 & 52.60 & 47.3 & 44.6 & 40.2 & 39.3 & 38.7
\end{tabular}

It can be seen from Table 6 that the speed of the trunk vehicle is $46.6 \mathrm{~km} / \mathrm{h}$, that is to say, when the traffic flow is $1200 \mathrm{veh}$ / h, the diversion of the slip road will be close to the limit, after which with the traffic flow increasing, the presence of the slip roads will increasingly aggravate congestion of urban traffic.

Table 6. Combination of Double-entrances Type III Residential Area and Two-way Straight Lanes (Traffic Flow is 1200veh/h)

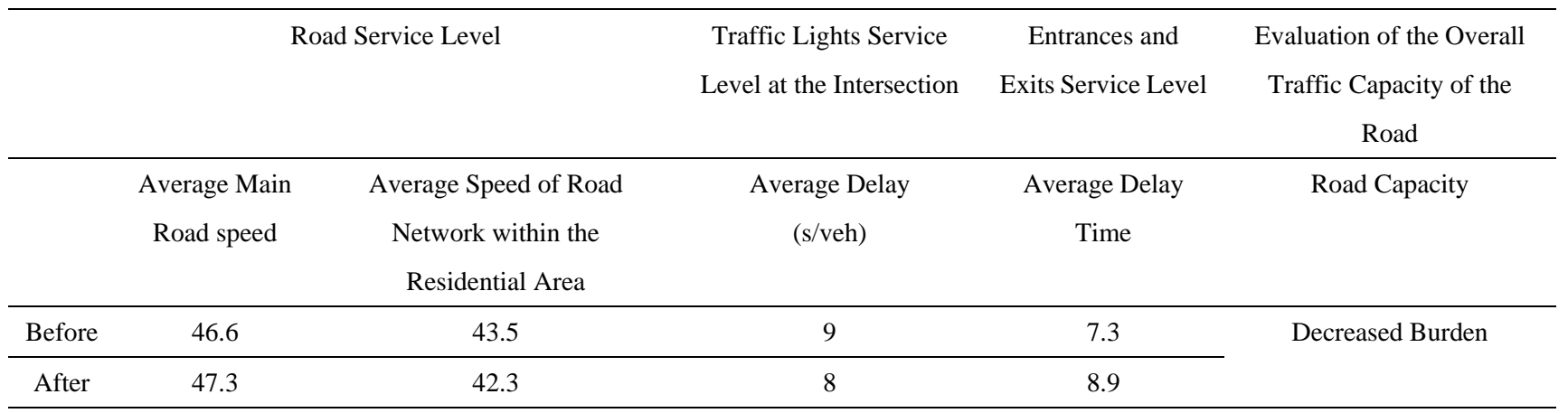

Therefore, when the trunk traffic flow is greater than $1200 \mathrm{veh} / \mathrm{h}$, the overall road capacity of double intersection type III will be reduced. When the trunk road traffic is about equal to $1200 \mathrm{veh} / \mathrm{h}$, the overall road capacity will reach the peak.

At the same time, when the vehicle speed in the residential area is about $47.3 \mathrm{~km} / \mathrm{h}$, the overall traffic capacity of double intersection type III is relatively decreased to some degree. So as long as the vehicle speed in the residential area is less than $47.3 \mathrm{~km} / \mathrm{h}$, the double intersection type III will not give the original road traffic burden.

\section{Conclusions}

According to the analysis of different types of open residential areas in this paper, conclusions are as follows:

(1)In four types of open residential areas, this paper found that the relief degree of traffic flow is shown as Figure4. Type (1) is best. Type (2) have the best effect of reducing traffic burden among double-entrance residential area. Type (4) not only cannot optimize the traffic flow, but also will aggravate traffic burden. So this paper suggests that the open residential area should be built in the area whose three sides are near the road. If condition does not allow, encouraging building type (2) will reduce the traffic burden properly. So this paper encourages the construction of type (1)(2) (3) and tries not to build the type (4). 


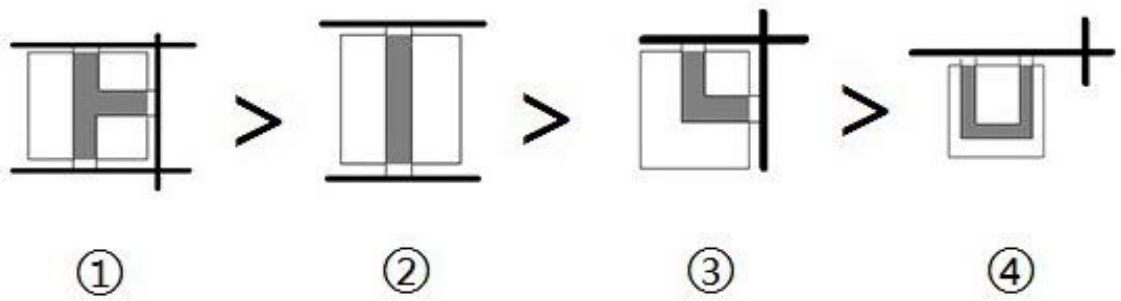

Figure 4. Effect of Reducing Traffic Burden of Open Community

(2) After the discussion, we conclude that type 4 will aggravate traffic burden. And the residential area of type 4 have the effect of sharing traffic flow only when the speed is limited in $47 \mathrm{~km} / \mathrm{h}$.

(3) During the rush hour, the traffic flow is often slow. Opening a slip road is equivalent to adding a blocked lane and the crowded road will bring inconvenience to residents. So we suggests that non-residential personnel should be prohibited on the road in the residential area during the morning and late peak.

(4) Due to the construction of open residential area will take up a lot of road space, it will bring inconvenience to the road if the car park in the central of the road. Therefore, this paper suggests that try to use the underground parking lot in the construction of open residential area.

(5) Try not to built the open residential area near the intersection with signal lights and had better keep a distance from other residential areas, teaching areas, institutions and other units.

\section{References}

Xianyan, K. (2014). Study on microscopic simulation modeling of urban mixed traffic flow[D].South China University of Technology.

Xiangpeng, L. (2014). Countermeasures of urban traffic congestion: A Study on traffic opening of closed community [D]. Changsha University of Science\&Technology.

Biao, Z. (2013). Study on the mechanism of congestion diffusion and its control and induced synergy model of intersection [D].JiLin University.

Long, J. (2015). Cellular automata simulation study on the driving state and the patency of non signal intersection [D]. Lanzhou Jiaotong University.

Feng, D. (2013). A comparative study of closed and western private communities in China [J].

Urban Problems, 2011, 11: 2-8.

Li Xiaofeng. Study on the planning strategy of urban residential district [D].Chang'an University, Zhiyong, H. (2007). Study on traffic impact analysis of residential district [D]. Huazhong University of Science and Technology.

Ge, Q. (2010). Research on the coordination between urban residential planning and urban transportation development [D]. Chang'an University.

\section{Copyrights}

Copyright for this article is retained by the author(s), with first publication rights granted to the journal.

This is an open-access article distributed under the terms and conditions of the Creative Commons Attribution license (http://creativecommons.org/licenses/by/4.0/). 